\title{
Recent Trends in Endoscopic Bariatric Therapies
}

\author{
Hyuk Soon Choi and Hoon Jai Chun \\ Division of Gastroenterology and Hepatology, Department of Internal Medicine, Institute of Gastrointestinal Medical Instrument Research, \\ Korea University College of Medicine, Seoul, Korea
}

\begin{abstract}
Obesity and its associated metabolic diseases including diabetes mellitus are severe medical problems that are increasing in prevalence worldwide and result in significant healthcare expenses. While behavioral and pharmacological treatment approaches are partly effective in the short term, their effects are not long-lasting. Although previous studies have described bariatric surgery as the most effective treatment for obesity, it is associated with morbidity, mortality, and economic burden. Endoluminal interventions performed entirely using gastrointestinal flexible endoscopy offer alternative approaches to the treatment of obesity that are safer and more costeffective than current surgical approaches. The use of endoluminal techniques in the field of metabolic obesity disease has diverse promising applications including endoscopic gastroplasty, intragastric balloon, endoluminal malabsorptive bariatric procedures, and gastric electrical stimulation (GES) for the modulation of gastric emptying. This review discusses recent trends and roles in endoscopic bariatric therapies using the currently available endoluminal and transgastric technologies. Clin Endosc 2017;50:11-16
\end{abstract}

Key Words: Obesity; Endoscopy; Bariatrics; Gastroplasty

\section{INTRODUCTION}

Obesity and its associated metabolic diseases, including cardiovascular diseases, diabetes mellitus, stroke, osteoarthritis, gastric esophageal reflux disease, and cancer, are severe medical problems that are increasing in prevalence worldwide. ${ }^{1}$ The World Health Organization defines obesity as an abnormal or excessive accumulation of adipose tissue that can be detrimental to health with considerable associated morbidity and mortality. ${ }^{2}$ A recent article on the trends of estimated mean body mass index (BMI) in 200 countries from 1975 to 2014 revealed that the prevalence of obesity was higher than that of underweight in 2014; this proportion was the opposite

Received: December 12, 2016 Revised: January 16, 2017

Accepted: January 17, 2017

Correspondence: Hoon Jai Chun

Division of Gastroenterology and Hepatology, Department of Internal Medicine, Institute of Gastrointestinal Medical Instrument Research, Korea University College of Medicine, Korea University Medical Center, 73 Inchon-ro, Seongbuk-gu, Seoul 02841, Korea

Tel: +82-2-920-5699, Fax: +82-2-953-1943, E-mail: drchunhj@chol.com

(cc) This is an Open Access article distributed under the terms of the Creative Commons Attribution Non-Commercial License (http://creativecommons.org/ licenses/by-nc/3.0) which permits unrestricted non-commercial use, distribution, and reproduction in any medium, provided the original work is properly cited. of that in 1975. The worldwide age-standardized mean BMI increased from $21.7 \mathrm{~kg} / \mathrm{m}^{2}$ in 1975 to $24.2 \mathrm{~kg} / \mathrm{m}^{2}$ in 2014 in men and from $22.1 \mathrm{~kg} / \mathrm{m}^{2}$ in 1975 to $24.4 \mathrm{~kg} / \mathrm{m}^{2}$ in 2014 in women. ${ }^{3}$ The prevalences of obesity in Asian, African, and Western countries have also increased substantially over the past decade. ${ }^{4}$

Despite recent debate about its criteria, obesity has a significant impact on mortality. ${ }^{5}$ According to this paper, median survival decreases in patients with a $\mathrm{BMI} \geq 30$. Furthermore, obesity is a complex public health problem that is commonly associated with an individual's economic environment. It has become an important social burden that results in significant economic burdens to healthcare systems. ${ }^{6}$

Numerous studies and developments are currently underway in an effort to solve this problem worldwide, including studies on obesity treatment drugs. However, several such drugs have been withdrawn due to complications; currently available drugs with less adverse effects have a weight reduction effect of approximately 5\%-11\% of the initial body weight. ${ }^{7}$ While behavioral and pharmacological treatment approaches are partly effective in the short-term, their effects are not long-lasting.

Bariatric surgery is currently the most effective and durable 
Table 1 . Types of Endoscopic Treatment Devices

\begin{tabular}{|c|c|c|}
\hline Title & Type & Products \\
\hline $\begin{array}{l}\text { Restrictive } \\
\text { endoscopic } \\
\text { procedures }\end{array}$ & Intragastric balloon & $\begin{array}{l}\text { Bioenterics Consecutive Balloon (Bioenterics Corporation, Carpentry, Allergan Inc., } \\
\text { Irvine, CA, USA)/Orbera Intragastric Balloon (Apollo Endosurgery, Austin, TX, } \\
\text { USA) } \\
\text { Ullorex Oral Intragastric Balloon (Obalon Therapeutics, Inc., San Diego, CA, USA/ } \\
\text { Phagia Technologies, Inc., USA) } \\
\text { Spatz Adjustable Intragastric Balloon (SpatzGFAR, Inc., NY, USA) } \\
\text { Heliosphere Bag (Helioscopie Medical Implants, Vienna, France) } \\
\text { Pear-shaped Semistationary Antral Balloon (JP Industria Farmacéutica S.A., Brazil) } \\
\text { Silimed Gastric Balloon (Slimed, Rio de Janeiro, Brazil) } \\
\text { Endogast-Adjustable Totally Implantable Intragastric Prosthesis (Districlass Medical } \\
\text { S.A., France) }\end{array}$ \\
\hline $\begin{array}{l}\text { Endoscopic } \\
\text { gastroplasty } \\
\text { techniques }\end{array}$ & Intragastric gastroplasty & $\begin{array}{l}\text { EndoCinch }^{\text {tix }} \text { (C.R. Bard Inc., Murray Hill, NJ, USA) } \\
\text { TOGA system (Satiety Inc., Palo Alto, CA, USA) } \\
\text { Esophyx (Boston Scientific Corp., Natick, MA, USA) } \\
\text { KUMC Successive Suturing Device (Korea University, Seoul, Korea) } \\
\text { Overstitch endoscopic suturing system (Apollo Endosurgery, Austin, TX, USA) } \\
\text { G Prox (USGI Medical, San Clemente, CA, USA) } \\
\text { NDO plicator (NDO Surgical, Mansfield, MA, USA) } \\
\text { OTSCs (Aponos, Kingston, NH, USA) } \\
\text { Incisionless Operating Platform (IOP; USGI Medical, San Clemente, CA, USA) }\end{array}$ \\
\hline $\begin{array}{l}\text { Malabsorptive } \\
\text { endoscopic } \\
\text { procedure }\end{array}$ & Malabsorptive stent & $\begin{array}{l}\text { Endobarrier (GI Dynamics, Inc., Watertown, MA, USA) } \\
\text { ValenTx device (ValenTx Inc., Carpinteria, CA, USA) } \\
\text { SatiSphere (Endosphere Inc., Columbus, OH, USA) }\end{array}$ \\
\hline $\begin{array}{l}\text { Evolving bariatric } \\
\text { endoscopic } \\
\text { technique }\end{array}$ & $\begin{array}{l}\text { Aspiration therapy } \\
\text { Gastro electrical } \\
\text { stimulator }\end{array}$ & $\begin{array}{l}\text { Aspire Assist (Aspire Bariatrics, King of Prussia, PA, USA) } \\
\text { Enterra/Transcend Implantable Gastric Stimulator (Transneuronix Inc. and Enterra } \\
\text { Therapy System, Medtronic, Minneapolis, MN, USA) } \\
\text { Endostim (EndoStim BV, The Hague, Netherlands) } \\
\text { Intrapace Abiliti Gastric Stimulator (Menlo Park, CA, USA) } \\
\text { Maestro VBLOCK therapy system (EnteroMedics, MN, USA) } \\
\text { the Diamond/Tantalus II system (Metacure, Kfar-Saba, Israel) }\end{array}$ \\
\hline
\end{tabular}

therapy for obesity. Various surgical methods have been established and applied to treat obesity for decades, such as Rouxen-Y gastric bypass (RYGB), vertical band gastroplasty, sleeve gastrectomy, and gastric band surgery. Each of these methods has its advantages and disadvantages; they also vary in efficacy. Recent bariatric surgical interventions aimed to reduce procedural complications and burden while maximizing the beneficial effects. Since bariatric surgery has been established as an alternative to diabetes mellitus treatment, it has attracted attention as a new treatment for this disease. ${ }^{8}$ However, although previous studies have described bariatric surgery as the most effective treatment for metabolic obesity disease, it is associated with a high morbidity rate, mortality rate, and economic burden. ${ }^{8,9}$ While the mortality rates of surgical interventions have decreased in recent years, the adverse events related to bariatric surgery remain considerably high. According to a meta-analysis study, the complication rate was $17 \%$ and the reoperation rate was $7 \% .{ }^{10}$ In addition, patient refusal to undergo surgery must be overcome.

Endoluminal interventions performed entirely by using

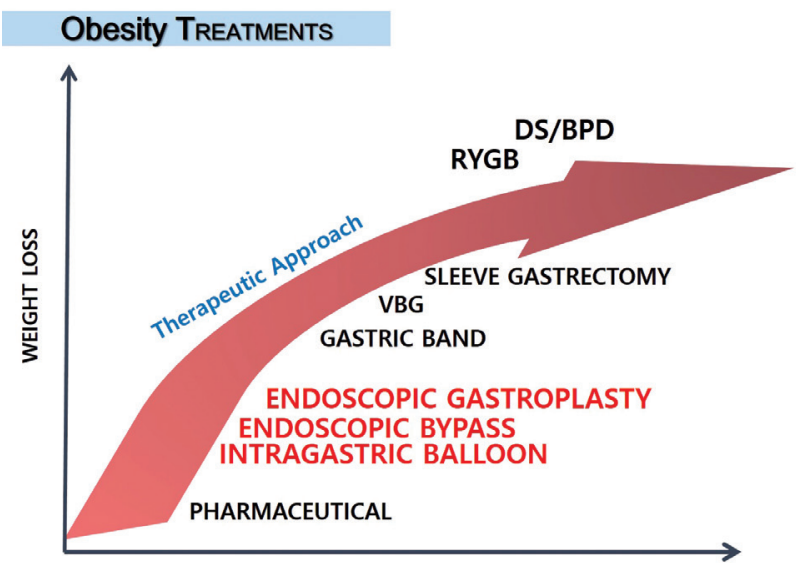

Fig. 1. Therapeutic approach to obesity treatment. The effect of endoscopic bariatric treatment for weight loss is greater than that of drugs but lower than that of bariatric surgery, but endoscopic bariatric treatment features fewer complications than bariatric surgery. VBG, vertical band gastroplasty; RYGB, Rouxen-Y gastric bypass; DS, duodenal switch; BPD, biliopancreatic diversion.

flexible gastrointestinal endoscopy offer an alternative approach to the treatment of obesity that is safer and more 
cost-effective than current surgical approaches. ${ }^{11}$ The use of endoluminal techniques in the field of metabolic obesity disease has several promising applications, such as endoscopic gastroplasty, intragastric balloon, endoluminal malabsorptive bariatric procedures, and gastric electrical stimulation (GES) for the modulation of gastric emptying (Table 1). The weight loss effects of endoscopic bariatric treatment are higher than drugs but lower than bariatric surgery, although the complications rates are less than the latter (Fig. 1).

Research on endoscopic obesity treatment is ongoing; in recent years, the treatment has accelerated in the United States and other countries. The range of diseases to which they are applied is also increasing, and a variety of items is currently being studied. This review will discuss recent trends and roles in endoscopic bariatric therapies using currently available endoluminal and transgastric technologies.

\section{ROLE OF RESTRICTIVE ENDOSCOPIC PROCEDURES IN OBESITY TREATMENT}

Intragastric balloons were developed to treat obesity by filling the stomach to induce early satiety. Although this technique was introduced 30 years ago, it was abandoned due to adverse events and balloon deflation. Since then, after several upgraded product developments, several intragastric balloons have been commercialized. The BioEnterics Intragastric Balloon (BIB; Allergan Inc., Irvine, CA, USA)/Orbera Intragastric Balloon (Apollo Endosurgery, Austin, TX, USA) has long been utilized for weight loss and is still used today. ${ }^{12,13}$ This device consists of a silicone balloon strong to gastric acid and a self-sealing valve that is filled with isotonic saline and methylene blue. In recent years, several other balloon devices for weight loss have been developed, such as the Ullorex Oral Intragastric Balloon (Obalon Therapeutics, Inc., San Diego, CA, USA/Phagia Technologies, Inc., USA), ${ }^{14}$ ReShape Duo ${ }^{\circledR}$ Integrated Dual Balloon System (ReShape Medical, San Clemente, CA, USA), BaroNova Polymer Pill (BaroNova Therapeutics Inc., Foster City, CA, USA), Spatz Adjustable Intragastric Balloon (SpatzGFAR, Inc., NY, USA), ${ }^{15}$ Heliosphere Bag (Helioscopie Medical Implants, Vienna, France), ${ }^{16}$ he Elipse ${ }^{\mathrm{mm}}$ (Allurion Technologies, Wellesley, MA, USA), pear-shaped Semistationary Antral Balloon (JP Industria Farmacéutica S.A., Brazil), ${ }^{17}$ Silimed Gastric Balloon (Slimed, Rio de Janeiro, Brazil), ${ }^{18}$ and Endogast-Adjustable Totally Implantable Intragastric Prosthesis (Districlass Medical S.A., France). ${ }^{2,9,19}$ However, these balloon devices also have several limitations, such as migration, rupture, gastric erosion, ulcers, perforation, technical problems, and clinical intolerance. ${ }^{1}$

The products that obtained European Conformite European
(CE) certification are awaiting Food and Drug Administration (FDA) approval, and additional clinical studies with intragastric balloons have been expected. A recent study reported meta-analyses using the existing Obera balloons. According to that study, weight loss (reduction rate of total body weight) was $11.3 \%$ and excess weight loss ([pre-treatment body weight - ideal body weight]/pre-treatment body weight) was $25.4 \% .{ }^{20}$ The American Society for Gastrointestinal Endoscopy suggested that endoscopic balloon therapy intended as a primary treatment for Class II/III obese persons (BMI $>35 \mathrm{~kg} / \mathrm{m}^{2}$ ) should achieve a mean minimum threshold of $25 \%$ excess weight loss measured at 12 months. ${ }^{21}$

However, these products also have several limitations. Common adverse events following intragastric balloon insertion include abdominal pain (33.7\%), gastroesophageal reflux disease (18.3\%), anorexia, and nausea (29\%). Severe complications such as gastric ulcers (2\%), small bowel obstruction $(0.3 \%)$, perforation $(0.1 \%)$, balloon migration ( $1.4 \%)$, and death $(0.08 \%)$ are less common. Early balloon removal occurred in $9.1 \%$ of the study participants due to patient intolerance. $^{22}$

\section{ROLE OF ENDOSCOPIC GASTROPLASTY TECHNIQUES IN THE MANAGEMENT OF OBESITY}

Endoluminal gastroplasty involves the reduction of gastric volume via the creation of a mucosa-to-mucosa tissue apposition, sleeve gastro mucosa-to-mucosa apposition, or stomach sleeve similar to surgical sleeve gastrectomy. Endoscopic gastroplasty uses natural orifice transluminal endoscopic surgery (NOTES) to reduce or eliminate the trauma of access incisions. The endoscopic suture device is the crucial device used in NOTES and endoluminal gastroplasty.

The currently available endoscopic suturing devices for human and animal studies include the following: EndoCinch ${ }^{\mathrm{mw}}$ (C.R. Bard Inc., Murray Hill, NJ, USA), TOGA system (Satiety Inc., Palo Alto, CA, USA), Esophyx (Boston Scientific Corp., Natick, MA, USA), KUMC Successive Suturing Device (Korea University, Seoul, Korea), Overstitch Endoscopic Suturing System (Apollo Endosurgery, Austin, TX, USA), G Prox (USGI Medical, San Clemente, CA, USA), NDO plicator (NDO Surgical, Mansfield, MA, USA), T-anchors (Ethicon Endo Surgery, Cincinnati, OH, USA), looped T-anchors (Cook Endoscopy, USA), OTSCs (Aponos, Kingston, NH, USA), and double-arm-bar suturing system (Hirohito Mori, Zeon Medical Co., Tokyo, Japan). ${ }^{23-27}$ However, each of these devices has several weaknesses, including safety, interrupted sutures, complicated installation, time-consuming use, and difficulty 
accessing upper gastric lesions. Although BaroSense (Redwood City, CA, USA) developed the Trans-oral Endoscopic Restrictive Implant System ${ }^{\mathrm{TM}}$ (TERIS), there are limited data on its use on humans and long-term efficacy. ${ }^{11}$

Several studies were recently conducted using the Incisionless Operating Platform (IOP; USGI Medical, San Clemente, CA, USA). The IOP system consists of a multi-lumen access device (Transport ${ }^{\circledR}$ ), endoluminal tissue approximator $(G$ Prox $^{\circledR}$ ), and suture anchors (Snowshoe ${ }^{\circledR}$ ). Recent research combining the Primary Obesity Surgery Endolumenal (POSE) procedure with the IOP system, such as the MILEPOST and Essential studies, have showed effective and safe results. ${ }^{28}$ This study showed that patients had a mean total weight loss of 17 $\mathrm{kg}$ at 1 year and an excess weight loss of $44 \%$ at 1 year after the POSE procedure.

The Overstitch (Apollo Endosurgery) is an FDA-approved therapeutic flexible endoscopic suturing device. Several endoscopic sleeve gastroplasty studies using the Overstitch have shown feasible and significant results. ${ }^{29,30}$ This study showed that patient had mean weight loss of $33 \mathrm{~kg}$ and excess weight loss of $30 \%$ after 6 months.

\section{ROLE OF MALABSORPTIVE ENDOSCOPIC PROCEDURE IN OBESITY TREATMENT}

Another endoscopic procedure for the treatment of metabolic obesity disease involves malabsorption techniques. The endoluminal malabsorptive device was designed for endoscopic duodenojejunal bypass, allowing for weight loss and control over diabetes mellitus. ${ }^{31,32}$ The proximal small bowel interventions are very efficient in blocking nutrient absorption; therefore, proximal small bowel bypass may contribute to obesity treatment and improved glucose control in diabetics.

The representative endoscopic malabsorptive product is the Endobarrier (GI Dynamics, Inc., Watertown, MA, USA), an intraluminal tube-shaped liner anchored in the bulb as a self-expanding metallic stent and located inside the duodenum to the proximal jejunum $(60 \mathrm{~cm})$. Several study results have been presented using this mechanism. A meta-analysis with duodenal-jejunal bypass sleeve revealed significant mean differences in body weight and an excess weight loss of -5.1 $\mathrm{kg}$ and $12.6 \%$, respectively, compared with conventional diet modification. However, the mean differences in glycated hemoglobin and fasting plasma glucose among patients with diabetes mellitus did not reach statistical significance. ${ }^{33}$

The ValenTx device (ValenTx Inc., Carpinteria, CA, USA) is a 120 -cm-long endoscopic gastroduodenojejunal sleeve that combines both gastric restriction and malabsorption techniques. The first clinical study with endoluminal gastroduode- nojejunal bypass sleeve reported 1-year implantation results. This study achieved excellent weight loss results, with a $54 \%$ mean percentage excess weight loss. They also showed that these results resolved and significantly improved over $70 \%$ of all co-morbidities. ${ }^{34}$ Another endoluminal mechanical device, the SatiSphere (Endosphere Inc., Columbus, OH, USA), is also implanted into the stomach and duodenum to delay the transit time of food and has shown effective short-term results in the treatment of obesity and metabolic disease. ${ }^{35}$

Clinical studies using the Duodenal Mucosal Resurfacing (DMR) system have been attempted in patients with diabetes mellitus and obesity. DMR is a minimally invasive catheter-based gastrointestinal endoscopic procedure that involves hydrothermal ablation of the duodenal mucosa and mucosal healing. It results in a clinically significant short-term glucose reduction with tolerable safety in patients with diabetes mellitus. $^{36}$

\section{EVOLVING BARIATRIC ENDOSCOPIC TECHNIQUE FOR OBESITY TREATMENT}

Several studies have been conducted since the introduction of aspiration therapy (Aspire Bariatrics, King of Prussia, PA, USA). Aspiration therapy includes the endoscopic placement of a gastrostomy tube and the AspireAssist siphon assembly to aspirate gastric contents 20-30 minutes after meal ingestion. This technique leverages the percutaneous endoscopic gastrostomy tube approach to induce weight loss by aspirating a proportion of consumed meals from the stomach. ${ }^{37} \mathrm{~A}$ clinical study using the AspireAssist aspiration therapy system of Sweden also showed substantial weight loss with few complications. $^{38}$ The AspireAssist system has several advantages and the potential as bridge therapy; however, alleviating patient repulsion has yet to be overcome.

GES, which is used to treat gastroparesis that is unresponsive to medical treatment, is awaiting FDA approval. GES devices are implanted subcutaneously along the abdominal wall, and they generate electrical pulses via bipolar leads in the muscular gastric layers.

GES systems were recently introduced to treat obesity. These devices stimulate a targeted gastric region and impair gastric electrical slow-wave activity, causing gastric distension, inhibiting peristalsis, and leading to delayed gastric emptying and increased satiety. ${ }^{39}$ Various GES devices have been developed and studied for metabolic obesity disease, such as the Enterra/Transcend Implantable Gastric Stimulator (Transneuronix Inc. and Enterra Therapy System, Medtronic, Minneapolis, MN, USA), the Endostim (EndoStim BV, The Hague, Netherlands), the Intrapace Abiliti Gastric Stimulator (Menlo 
Park, CA, USA), Maestro VBLOCK therapy system (EnteroMedics, MN, USA), and the Diamond/Tantalus II system (Metacure, Kfar-Saba, Israel). ${ }^{32,40}$ These devices were recently approved by the FDA as a treatment for obesity. However, the limitations of these devices include lead dislodgement, lack of a long-term effect, and surgical risks. The placement of a permanent GES device currently requires surgery and considerable cost. More importantly, this method of therapy may not be effective for all patients. Several GES systems have been applied in humans as a treatment for obesity and metabolic disease, while several clinical studies have shown significant results with fewer adverse events. In a multicenter randomized comparative study of a GES group and a laparoscopic gastric band group, the GES therapy group showed non-inferiority results compared with the laparoscopic gastric band group. There were significantly fewer and less severe adverse effects in the GES group than in the laparoscopic gastric band group. ${ }^{39,41,42}$ Recent endoscopic installation trials of GES devices have shown minimal effectiveness in animal studies. ${ }^{42-45}$ This technology is expected to be applied to gastrointestinal endoscopy in the future.

\section{CONCLUSION}

Obesity is a chronic relapsing multi-factorial disease that is associated with substantial morbidity and mortality. Most therapeutic approaches to weight loss include lifestyle modification, pharmacotherapy, and bariatric surgery. Recent advances in endoluminal technology for the treatment of obesity and metabolic diseases have been promising. Reversible approaches that do not require the patient to commit to permanent surgical modifications of the gastrointestinal tract are of particular interest. Endoscopic bariatric treatment must be an attractive option to both patients and physicians. The application of endoscopic bariatric technology as a treatment for obesity remains ambiguous; however, with more research of evidence overcoming previous therapeutic limitations, endoscopic bariatric therapy will find its role in obesity treatment.

The overall treatment of obesity requires a multidisciplinary team approach. Diet, nutrition, physical activity, and behavioral modifications are important along with several medical tools that support adherence to low-calorie food intake. The development of new endoscopic techniques allows the endoscopist to play an increasingly important role in the management of obesity. There is also hope that minimally invasive endoscopic technological advancements will lead to an effective therapy to help the millions of people currently afflicted with metabolic obesity disease worldwide. Each device will require careful assessment through clinical trials to determine their safety, efficacy, and durability. Finally, the endoscopic bariatric approach will have the initiative in a continuum of obesity treatment care.

\section{Conflicts of Interest}

The authors have no financial conflicts of interest.

\section{Acknowledgments}

This study was supported by a grant from the Korea Health Technology R\&D Project through the Korea Health Industry Development Institute (KHIDI) funded by the Ministry of Health \& Welfare, Republic of Korea (grant number: HI14C3477) and the Basic Research Program through the National Research Foundation of Korea (NRF-2014R1A2A2A01006131).

\section{REFERENCES}

1. ASGE Bariatric Endoscopy Task Force; ASGE Technology Committee, Abu Dayyeh BK, et al. Endoscopic bariatric therapies. Gastrointest Endosc 2015;81:1073-1086.

2. Espinet-Coll E, Nebreda-Durán J, Gómez-Valero JA, et al. Current endoscopic techniques in the treatment of obesity. Rev Esp Enferm Dig 2012;104:72-87.

3. NCD Risk Factor Collaboration (NCD-RisC). Trends in adult bodymass index in 200 countries from 1975 to 2014: a pooled analysis of 1698 population-based measurement studies with 19.2 million participants. Lancet 2016;387:1377-1396.

4. Lee CM, Colagiuri S, Ezzati M, Woodward M. The burden of cardiovascular disease associated with high body mass index in the Asia-Pacific region. Obes Rev 2011;12:e454-e459.

5. Prospective Studies Collaboration, Whitlock G, Lewington S, et al. Body-mass index and cause-specific mortality in 900000 adults: collaborative analyses of 57 prospective studies. Lancet 2009;373:1083-1096.

6. Hammond RA, Levine R. The economic impact of obesity in the United States. Diabetes Metab Syndr Obes 2010;3:285-295.

7. Gotthardt JD, Bello NT. Can we win the war on obesity with pharmacotherapy? Expert Rev of Clin Pharmacol 2016;9:1289-1297.

8. Schauer PR, Bhatt DL, Kirwan JP, et al. Bariatric surgery versus intensive medical therapy for diabetes--3-year outcomes. N Engl J Med 2014;370:2002-2013.

9. ASGE Technology Committee, Kethu SR, Banerjee S, et al. Endoluminal bariatric techniques. Gastrointest Endosc 2012;76:1-7.

10. Chang SH, Stoll CR, Song J, Varela JE, Eagon CJ, Colditz GA. The effectiveness and risks of bariatric surgery: an updated systematic review and meta-analysis, 2003-2012. JAMA Surg 2014;149:275-287.

11. Stimac D, Majanović SK. Endoscopic approaches to obesity. Dig Dis 2012;30:187-195

12. Alfredo G, Roberta M, Massimiliano C, Michele L, Nicola B, Adriano R. Long-term multiple intragastric balloon treatment-a new strategy to treat morbid obese patients refusing surgery: prospective 6-year follow-up study. Surg Obes Relat Dis 2014;10:307-311.

13. Lopez-Nava G, Rubio MA, Prados S, et al. BioEnterics intragastric balloon $\left(\mathrm{BIB}^{\star}\right)$. Single ambulatory center Spanish experience with 714 consecutive patients treated with one or two consecutive balloons. Obes Surg 2011;21:5-9.

14. Mion F, Ibrahim M, Marjoux S, et al. Swallowable Obalon ${ }^{\circ}$ gastric balloons as an aid for weight loss: a pilot feasibility study. Obes Surg 2013;23:730-733.

15. Machytka E, Klvana P, Kornbluth A, et al. Adjustable intragastric balloons: a 12-month pilot trial in endoscopic weight loss management. Obes Surg 2011;21:1499-1507.

16. Trande P, Mussetto A, Mirante VG, et al. Efficacy, tolerance and safety 
of new intragastric air-filled balloon (Heliosphere BAG) for obesity: the experience of 17 cases. Obes Surg 2010;20:1227-1230.

17. Lopasso FP, Sakai P, Gazi BM, et al. A pilot study to evaluate the safety, tolerance, and efficacy of a novel stationary antral balloon (SAB) for obesity. J Clin Gastroenterol 2008;42:48-53.

18. Carvalho GL, Barros CB, Moraes CE, et al. The use of an improved intragastric balloon technique to reduce weight in pre-obese patients-preliminary results. Obes Surg 2011;21:924-927.

19. Gaggiotti G, Tack J, Garrido AB Jr, Palau M, Cappelluti G, Di Matteo F. Adjustable totally Implantable intragastric prosthesis (ATIIP) - Endogast for treatment of morbid obesity: one-year follow-up of a multicenter prospective clinical survey. Obes Surg 2007;17:949-956.

20. Gaur S, Levy S, Mathus-Vliegen L, Chuttani R. Balancing risk and reward: a critical review of the intragastric balloon for weight loss. Gastrointest Endosc 2015;81:1330-1336.

21. ASGE Bariatric Endoscopy Task Force, ASGE Technology Committee, Abu Dayyeh BK, et al. ASGE bariatric endoscopy task force systematic review and meta-analysis assessing the ASGE PIVI thresholds for adopting endoscopic bariatric therapies. Gastrointest Endosc 2015;82:425-438.e5.

22. Kim SH, Chun HJ, Choi HS, Kim ES, Keum B, Jeen YT. Current status of intragastric balloon for obesity treatment. World J Gastroenterol 2016;22:5495-5504.

23. ASGE Technology Committee, Banerjee S, Barth BA, et al. Endoscopic closure devices. Gastrointest Endosc 2012;76:244-251.

24. Abu Dayyeh BK, Rajan E, Gostout CJ. Endoscopic sleeve gastroplasty: a potential endoscopic alternative to surgical sleeve gastrectomy for treatment of obesity. Gastrointest Endosc 2013;78:530-535.

25. Song Y, Choi HS, Kim K, et al. A simple novel endoscopic successive suture device: a validation study for closure strength and reproducibility. Endoscopy 2013;45:655-660

26. Mori H, Kobara H, Fujihara S, et al. Feasibility of pure EFTR using an innovative new endoscopic suturing device: the double-arm-bar suturing system (with video). Surg Endosc 2014;28:683-690.

27. Kim Y, Choi HS, Kim K, et al. A novel endoscopic surgical device for gastric volume reduction bariatric surgery. International Journal of Precision Engineering and Manufacturing 2016;17:467-472.

28. López-Nava G, Bautista-Castaño I, Jimenez A, de Grado T, Fernandez-Corbelle JP. The primary obesity surgery endolumenal (POSE) procedure: one-year patient weight loss and safety outcomes. Surg Obes Relat Dis 2015;11:861-865.

29. Lopez-Nava G, Galvão MP, Bautista-Castaño I, Jimenez-Baños A, Fernandez-Corbelle JP. Endoscopic sleeve gastroplasty: how I do it? Obes Surg 2015;25:1534-1538.

30. Sharaiha RZ, Kedia P, Kumta N, et al. Initial experience with endoscopic sleeve gastroplasty: technical success and reproducibility in the bariatric population. Endoscopy 2015;47:164-166.

31. Rohde U, Hedbäck N, Gluud LL, Vilsbøll T, Knop FK. Effect of the En-
doBarrier gastrointestinal liner on obesity and type 2 diabetes: protocol for systematic review and meta-analysis of clinical studies. BMJ Open 2013;3:e003417.

32. Rodriguez L, Rodriguez P, Gómez B, et al. Long-term results of electrical stimulation of the lower esophageal sphincter for the treatment of gastroesophageal reflux disease. Endoscopy 2013;45:595-604.

33. Rohde U, Hedbäck N, Gluud LL, Vilsbøll T, Knop FK. Effect of the EndoBarrier gastrointestinal liner on obesity and type 2 diabetes: a systematic review and meta-analysis. Diabetes Obes Metab 2016;18:300305.

34. Sandler BJ, Rumbaut R, Swain CP, et al. One-year human experience with a novel endoluminal, endoscopic gastric bypass sleeve for morbid obesity. Surg Endosc 2015;29:3298-3303.

35. Sauer N, Rösch T, Pezold J, et al. A new endoscopically implantable device (SatiSphere) for treatment of obesity--efficacy, safety, and metabolic effects on glucose, insulin, and GLP-1 levels. Obes Surg 2013;23:17271733.

36. Rajagopalan H, Cherrington AD, Thompson CC, et al. Endoscopic duodenal mucosal resurfacing for the treatment of type 2 diabetes: 6-month interim analysis from the first-in-human proof-of-concept study. Diabetes Care 2016;39:2254-2261.

37. Sullivan S, Stein R, Jonnalagadda S, Mullady D, Edmundowicz S. Aspiration therapy leads to weight loss in obese subjects: a pilot study. Gastroenterology 2013;145:1245-1252.el-e5.

38. Forssell H, Norén E. A novel endoscopic weight loss therapy using gastric aspiration: results after 6 months. Endoscopy 2015;47:68-71.

39. Horbach T, Meyer G, Morales-Conde S, et al. Closed-loop gastric electrical stimulation versus laparoscopic adjustable gastric band for the treatment of obesity: a randomized 12-month multicenter study. Int J Obes (Lond) 2016;40:1891-1898.

40. Verdam FJ, Schouten R, Greve JW, Koek GH, Bouvy ND. An update on less invasive and endoscopic techniques mimicking the effect of bariatric surgery. J Obes 2012;2012:597871.

41. Lebovitz HE, Ludvik B, Yaniv I, et al. Treatment of patients with obese type 2 diabetes with tantalus-DIAMOND ${ }^{\circ}$ gastric electrical stimulation: normal triglycerides predict durable effects for at least 3 Years. Horm Metab Res 2015;47:456-462.

42. Chiu JD, Soffer E. Gastric electrical stimulation for obesity. Curr Gastroenterol Rep 2015;17:424.

43. Abell TL, Johnson WD, Kedar A, et al. A double-masked, randomized, placebo-controlled trial of temporary endoscopic mucosal gastric electrical stimulation for gastroparesis. Gastrointest Endosc 2011;74:496503.e3.

44. Ayinala S, Batista O, Goyal A, et al. Temporary gastric electrical stimulation with orally or PEG-placed electrodes in patients with drug refractory gastroparesis. Gastrointest Endosc 2005;61:455-461.

45. Lonys L, Vanhoestenberghe A, Huberty V, et al. Design and implementation of a less invasive gastrostimulator. Eur J Transl Myol 2016;26:6019. 